\title{
Cigarette smoking and gastrointestinal diseases: The causal relationship and underlying molecular mechanisms (Review)
}

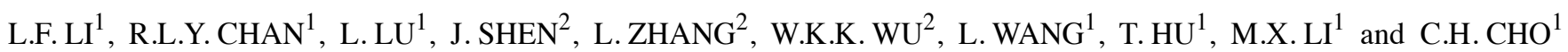 \\ ${ }^{1}$ School of Biomedical Sciences, Faculty of Medicine, ${ }^{2}$ Institute of Digestive Diseases, \\ Prince of Wales Hospital, The Chinese University of Hong Kong, Hong Kong SAR, P.R. China
}

Received April 24, 2014; Accepted May 20, 2014

DOI: $10.3892 / \mathrm{ijmm} .2014 .1786$

\begin{abstract}
Cigarette smoking is an important risk factor for gastrointestinal (GI) disorders, including peptic ulcers, inflammatory bowel diseases, such as Crohn's disease and cancer. In this review, the relationship between smoking and GI disorders and the underlying mechanisms are discussed. It has been demonstrated that cigarette smoking is positively associated with the pathogenesis of peptic ulcers and the delay of ulcer healing. Mechanistic studies have shown that cigarette smoke and its active ingredients can cause mucosal cell death, inhibit cell renewal, decrease blood flow in the GI mucosa and interfere with the mucosal immune system. Cigarette smoking is also an independent risk factor for various types of cancer of the GI tract. In this review, we also summarize the mechanisms through which cigarette smoking induces tumorigenesis and promotes the development of cancer in various sections of the GI tract. These mechanisms include the activation of nicotinic acetylcholine receptors, the formation of DNA adducts, the stimulation of tumor angiogenesis and the modulation of immune responses in the GI mucosa. A full understanding of these pathogenic mechanisms may help us to develop more effective therapies for GI disorders in the future.
\end{abstract}

\section{Contents}

1. Introduction

2. Cigarette smoking increases the risk of ulcers and inflammatory diseases of the GI tract

3. Smoking increases the risk of cancer of the GI tract

4. Conclusions

Correspondence to: Professor Chi-Hin Cho or Dr Long-Fei Li, School of Biomedical Sciences, Faculty of Medicine, The Chinese University of Hong Kong, Shatin, NT, Hong Kong SAR, P.R. China

E-mail: chcho@cuhk.edu.hk

E-mail: lee130428@163.com

Key words: smoking, gastrointestinal diseases, inflammation, cancer

\section{Introduction}

Cigarette smoking is the most preventable risk factor for human health. According to a WHO report, 1.3 billion individuals are active smokers worldwide and smoking kills six million individuals each year; eventually, half of these smokers die due to smoking-related diseases (1). To this end, cigarette smoking is known to be associated with cardiovascular diseases (2), cancers $(3,4)$, lung diseases (5), chronic renal disorders (6) and other diseases remained to be defined. It has been regarded as a main killer and induces serious problems in humans with major concerns in public health.

Over 5,000 ingredients are found in cigarette smoke $(7,8)$. Among these, at least 150 compounds found in cigarette smoke are known to induce free radicals and possess toxic and carcinogenic activities. Based on their structures, these toxic and carcinogenic ingredients are divided into several chemical classes. These include alkaloids, phenolic compounds, volatile aldehydes, polycyclic aromatic hydrocarbons (PAHs), tobaccospecific nitrosamines (TNSAs), as well as heavy metals (8). These chemical induce high levels of oxidative stress in smokers (7), and trigger and augment lipid peroxidation, which causes low-density lipoprotein (LDL) oxidation and atherosclerosis (9). These active ingredients also cause a high incidence of lung cancer accounting for approximately $90 \%$ of small cell lung cancer (SCLC) cases and $70 \%$ of non-small cell lung cancer (NSCLC) cases worldwide (10).

A number of studies have provided evidence that cigarette smoking is a major cause of gastrointestinal (GI) disorders, which include chronic inflammation, such as peptic ulcers and inflammatory bowel disease (IBD), and cancers of the GI tract (1,3-8). In this review, we mainly discuss the relationship between smoking and GI disorders, and the underlying mechanisms through which cigarette smoke and its active ingredients affect the pathogenic processes of some of these diseases of the GI tract.

2. Cigarette smoking increases the risk of ulcers and inflammatory diseases of the GI tract

Cigarette smoking increases the risk of peptic ulcer disease. Peptic ulcers are histologically identified as necrosis of the mucosa, which produces lesions. This disease is mainly caused 
by Helicobacter pylori (H.pylori) infection, as well as the excessive use of non-steroidal anti-inflammatory drugs (NSAIDs), such as aspirin and ibuprofen (11). Cigarette smoking is also considered to be one of the major contributors to ulcer diseases. A large US population-based study (1997-2003) revealed that the prevalence of ulcer disease in current and former smokers (11.43 and $11.52 \%)$ is almost doubled that of never smokers $(6.00 \%)(12)$. It is also clear that the risk of peptic ulcers is associated with the quantity of tobacco use (13).

According to clinical observations, cigarette smokers are more likely to develop ulcers which are more difficult to heal (14). The risk of peptic ulcers also increases in smokers who have a large daily intake of tobacco compared with never smokers (15). However, cigarette smoking is not an independent ulcerogenic. It adversely affects the gastroduodenal mucosal protective mechanisms and increases the risk of $H$. pylori infection (14). Cigarette smoking allows the reflux of harmful duodenal contents back into the stomach. Furthermore, smokers appear to be at higher risk of becoming infected with H. pylori. This increased risk may be due to the adverse effects of smoking on the reduction of antioxidants or the defensive immune system locally present in the gastroduodenal mucosa. All these actions can interfere with the natural defensive mechanisms against $H$. pylori infection in the stomach and duodenum.

Effects of smoking on IBD. IBD is known as chronic inflammation of the GI tract, particularly the colon and small intestine. IBD includes Crohn's disease and ulcerative colitis (16). Cigarette smoking exerts a dichotomous effect in the progression of IBD. Smokers seem to be more likely to develop Crohn's disease, with a higher recurrence after surgery and poor response to medications $(17,18)$. However, people who smoke have a lower risk of developing ulcerative colitis (19). Cigarette smoking is known as an independent risk factor for Crohn's disease. As early as 1984, a case-control study involving 82 patients with Crohn's disease and matched controls was conducted in the UK to determine the relationship between Crohn's disease and cigarette smoking (20). Patients with this disease were more likely to have a smoking habit. The relative risk for smokers to develop Crohn's disease was significantly higher than in non-smokers (20). In a separate study involving 2,795 patients with Crohn's disease, patients were classified into non-smokers, light smokers (1-10 cigarettes/day) and heavy smokers ( $>10$ cigarettes/day). Researchers found that the percentage of years with active Crohn's disease for nonsmokers, light smokers and heavy smokers were 37, 46 and $48 \%$, respectively. Besides, the number of years of immumosuppressant mediation was higher in the heavy smokers than the light smokers and non-smokers (36 vs. 34 vs. 32\%, respectively) (21). These results suggest that smoking may worsen the severity of the disease and prolong the disease course and drug treatment with immunosuppressants.

Conversely, smoking has been demonstrated to reduce the risk of ulcerative colitis. Mounting evidence has indicated that patients with ulcerative colitis tend to be non-smokers (22). In a population-based incident cohort study, smoking was more common in male patients $(\mathrm{P}=0.002)$, and positively correlated with an increased risk of Crohn's disease [odds ratio, 1.96; 95\% confidence interval $(\mathrm{CI}), 1.63-2.37 ; \mathrm{P}<0.001]$. By contrast, current smoking was protective against ulcerative colitis (odds ratio, 0.33 ; 95\% CI, 0.27-0.41). In addition, in ulcerative colitis, cigarette smoking was associated with less extensive disease $(\mathrm{P}=0.01)$ and a decreased need for colectomy $(\mathrm{P}=0.06)(23)$. The underlying mechanisms of action of smoking and its bidirectional effects on the progression of Crohn's disease and ulcerative colitis have not yet been fully elucidated and further studies are required using human and animal models.

Possible mechanisms of action of smoking in inflammatory diseases of the GI tract. As discussed, cigarette smoking is a major risk factor for the development of inflammation-related diseases, such as ulcers and Crohn's disease. In Fig. 1, the mechanisms of action of smoking in these disorders include the alteration of mucosal cell proliferation, change of blood flow in the inflammatory sites, the increase of viral or bacterial infections and the dysfunction of the immune system in the GI mucosa.

Smoking induces cell death in the mucosa. The mucosa is the inner layer of the GI tract, which surrounds the lumen. The innermost layer is known as the epithelium, which forms a continuous layer of protection against noxious agents from the lumen. The induction of cell apoptosis is an adverse effect of cigarette smoking, which results in tissue injury and dysfunction in the GI tract. A number of studies have shown that cigarette smoke can induce cell apoptosis in the esophagus and gastric mucosa (24), as well as in the inner layers of the small intestine and colon (25). Exposure to cigarette smoke induces a time- and concentration-dependent increase in apoptosis in the gastric mucosa (26). Pre-treatment with allopurinol (a xanthine oxidase inhibitor) or dimethyl sulfoxide (DMSO) (a hydroxyl free radical scavenger) can block the apoptotic activity induced by smoking, and does not affect the p53 level of the mucosa (26), suggesting that the apoptosis induced by cigarette smoking is mediated through reactive oxygen species (ROS) and occurs independently of the p53 pathway. Chronic exposure to cigarette smoke can also induce apoptosis in the follicle-associated epithelium, possibly through the CCL20-CCR6 cascade (25). Benzo(e)pyrene, a toxic compound found in cigarette smoke, also causes cell death in human retinal pigment epithelial cells (ARPE-19), and induces apoptosis through the involvement of multiple caspase pathways (27).

Smoking inhibits epithelial cell renewal in the GI tract. Epithelial cell renewal in the GI tract is an effective progress for protecting the surface epithelial cells from various aggressive factors coming from the lumen. The effects of cigarette smoking on cell renewal in the GI tract have been reviewed by a number of studies showing that cigarette smoke and its active ingredients not only inhibit mucosal cell proliferation, but also induce cell apoptosis during ulcer healing $(8,24)$. Cell renewal is a protective process for the GI tract, the dysfunction of which plays a vital role in ulceration and ulcer healing (28). We have previously reviewed that cigarette smoke and its active ingredients can suppress mucosal cell proliferation and induce apoptosis during ulceration and the healing processes $(8,24)$.

Epidermal growth factor $(E G F)$. In our previous studies we demonstrated that cigarette smoke or its extracts significantly inhibit mucosal cell proliferation in human and animal mucosal cells, associated with the reduction of EGF and poly- 


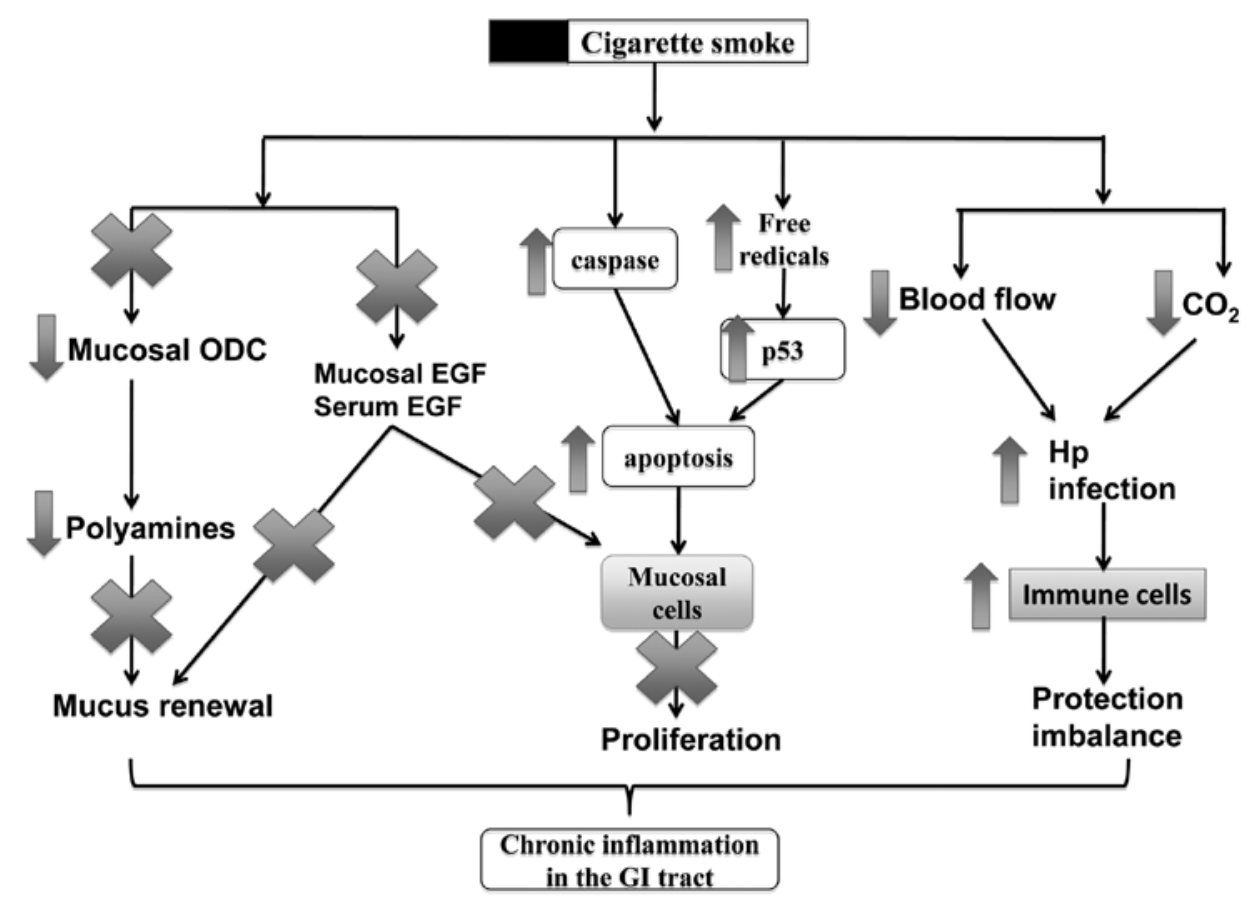

Figure 1. Possible mechanisms of action of cigarette smoke in inducing chronic inflammation in the GI tract. GI, gastrointestinal; ODC, ornithine decarboxylase; EGF, epidermal growth factor; Hp, Helicobacter pylori.

amine release $(29,30)$. EGF plays an important role in mucosal cell proliferation and modulates mucosal integrity. During ulceration, the synthesis of EGF, as well as its expression are markedly upregulated in epithelial cells adjacent to the ulcer crater (31). Data from our previous study also demonstrated that cigarette smoke significantly inhibited EGF synthesis and its mRNA expression in salivary glands and gastric mucosa in rats with acetic acid ulcers (29). In addition, gastric ulcer healing was also delayed along with a reduced mucosal cell proliferation, suggesting that the delay of ulcer healing induced by cigarette smoke is possibly caused by the reduction of EGF release at the ulcer site.

Polyamines. Polyamines are found to be associated with mucosal cell proliferation during the ulcer healing process $(32,33)$. Polyamines are involved in EGF-mediated cell proliferation and acid secretion in the stomach (34). Ornithine decarboxylase (ODC) is the primary enzyme for the biosynthesis of polyamines, including putrescine, spermine and spermidine. To further elucidate the association between smoking and peptic ulcer disease, in previous studies, we also examined ODC activity, which is crucial for promoting mucosal growth and has gastroprotective effects during gastric ulcer healing. Following the intragastric administration with cigarette smoke extracts once daily for three days, ulcer sizes were markedly enlarged and the myeloperoxidase activity was also increased. Cigarette smoke also significantly inhibited cell migration and cell proliferation with a reduction in ODC activity in an in vitro wound model. Moreover, the inhibitory effect on cell proliferation and ODC activity induced by cigarette smoke may be reversed by exogenous spermidine, indicating that the delayed wound healing in the stomach induced by cigarette smoke was at least in part due to a reduction in polyamine synthesis $(30,32)$.
Smoking interferes with GI mucosal protective mechanisms Stomach acid secretion. Under normal conditions, large amounts of hydrochloric acid exist in the stomach, which help to break down food into smaller particles for further digestion in the digestive tract. Gastric acid is neutralized in the duodenum by sodium bicarbonate produced by the pancreas. The increased secretion of stomach acid and/or a reduction in sodium bicarbonate production in the pancreas can interfere with the protective mechanisms of the gastric mucosa and the inner layer of the duodenum, where ulcers are normally formed. Ample evidence suggests that smoking can increase the production of gastric acid, accompanied by a reduction in bicarbonate production. The role of cigarette smoke and its active compounds, such as nicotine on acid production and sodium bicarbonate production has been reviewed (35). Researchers have found that the intravenous injection of nicotine hydrogen tartrate $(0.012-0.020 \mathrm{mg} / \mathrm{kg}$ body weight) increases the concentration of hydrogen and chloride ions in the gastric juice (36). In an early study, Ligny et al (37) demonstrated that the magnitude of acid secretion was associated with the number of cigarettes smoked. They also found that tobacco smoking over a long period of time stimulated vagus nerves and induced functional parietal cells to increase pentagastrin-induced acid output in smokers.

Biliary reflux. Bile is a digestive fluid produced by the liver, and normally flows into the duodenum, where it digests fats and removes toxins. Bile salts also function as detergents and damage the mucosal barrier. The pylorus is a one-way valve between the stomach and the duodenum that prevents bile and other contents of the small intestine going back into the stomach (38). In a clinical study, it was demonstrated that cigarette smoking induces pyloric incompetence and increases the duodenogastric reflux (39), which may be due to the reduction 
in basal pyloric pressure induced by smoking (40), leading to mucosal injury in the stomach.

Pancreatic bicarbonate secretion. Pancreatic bicarbonate plays an important role in neutralizing extra acid coming from the stomach. The increased secretion of gastric acid, as well as a reduction in sodium bicarbonate production would interfere with the protective mechanisms in the stomach and the duodenum, possibly leading to the development of ulcers in these organs. Several clinical studies have shown that the secretion of bicarbonate is diminished after cigarette smoking $(41,42)$. Furthermore, the degree of inhibition on basal pancreatic secretion has been shwon to have a good correlation with the blood nicotine concentrations in humans (43).

Smoking increases susceptibility to $H$. pylori infection. $H$. pylori is known as one of the most common infectious bacteria found in humans (44). Growing evidence points to a potential association between $H$. pylori infection and GI disorders, including gastroduodenal ulcers and cancer (45). Although some researchers have found that cigarette smoking is negatively associated with $H$. pylori infection, particularly in younger subjects (46), other epidemiological and experimental studies have indicated that smoking is also a risk factor for $H$. pylori infection at least under certain clinical conditions $(47,48)$.

Free radicals. Free radicals have been related to a wide spectrum of GI disorders, including ulcers, IBDs and GI cancers. Oxygen-derived free radicals play an important role in the pathogenesis of peptic ulcers and IBD induced by smoking, alcohol, as well as NSAIDs (49-51). Cigarette smoke contains large amounts of free radicals (52). The quinone/hydroquinone complex, for example, is an active redox system which is capable of decreasing molecular oxygen to produce superoxide, eventually transforming to hydrogen peroxide and hydroxyl radicals (52). The blood concentrations of free radicals in smokers are higher than those of non-smokers, indicating that smoking-induced free radicals promote gastric mucosal injury (53).

Smoking regulates immune cells in the GI tract. The GI tract is also protected by the local mucosal immune system operating in the GI mucosa against various internal and external pathogens (8). Chronic exposure to cigarette smoke and its active ingredients has also been demonstrated to lead to alterations in the immune system (54). Macrophages, neutrophils, lymphocytes and dendritic cells may be involved in the pathogenesis of inflammatory disorders in the GI tract. A research group found that chronic smoke exposure was positively associated with immune cell accumulation in Peyer's patches. The total number of dendritic cells, $\mathrm{CD} 4^{+} \mathrm{T}$ cells (including regulatory $\mathrm{T}$ cells) and $\mathrm{CD} 8^{+} \mathrm{T}$ cells was significantly increased following exposure to cigarette smoke for 24 weeks (25). Furthermore, the expression of chemokines, including CCL9 and CCL20 was also upregulated, which may play an important role in the pathogenesis of Crohn's disease. Smoke exposure also increases xanthine oxidase activity and histamine release in the gastric mucosa. This may further lead to neutrophil aggregation and vascular damage, thus promoting gastric ulcers in rats $(55)$.

\section{Smoking increases the risk of cancer of the GI tract}

As stated in the previous section, tobacco smoking induces various chronic inflammatory diseases of the GI tract, including ulcers. It is clearly understood that chronic inflammation can cause tumor initiation through the induction of genomic instability, leading to mutagenesis (56). In addition, cigarette smoke contains a broad spectrum of toxic and carcinogenic components, such as aromatic amines, phenolic compounds, alkaloids, PAHs, TNSAs, as well as heavy metals $(7,8)$. Among these, aromatic amines are thought to be the inducers of bladder cancer, and TNSAs are thought to contribute to lung cancer in smokers (57). Nicotine, taken as an example, is known as the most active ingredient in cigarette smoke, which is as high as $0.3-5 \%$ of the dry weight in tobacco leaves (58). It has been found that nicotine plays an important role in gastroduodenal ulceration (35) and Crohn's disease. Furthermore, it also promotes cancer development in the esophagus (59), stomach (4), colon (60) and liver (61).

\section{Epidemiological studies}

Cigarette smoking causes esophageal cancer. Cigarette smoking is one of the risk factors for esophageal cancer (62-65). Recently, a cohort study with a 20 -year follow-up period conducted by Japanese researchers found that individuals who began smoking at a younger age and consumed larger amounts of alcohol more had a higher risk of developing esophageal cancer compared with the normal population. The esophageal cancer mortality risk was as high as 9.33 (95\% CI, 2.55-34.2) for smokers who began smoking between the ages of 10 and 19 years and consuming three units of alcohol per day (64).

Cigarette smoking and cancer of the oral cavity. Supporting data have demonstrated that cigarette smoking is a major risk factor for cancer of the oral cavity (66-68). A recent study demonstrated that the odds ratios for current smokers and former smokers were 11.8 (95\% CI, 8.6-16.3) and 2.2 (95\% CI, 1.6-3.1), respectively when compared to non-smokers. The risk of developing cancer of the oral cavity increased with the quantity and duration of cigarette smoking (66). In addition, the risk of developing cancer of the oral cavity in former smokers decreased with time. The buccal mucosa and the floor of the mouth were the most sensitive sites with lesions induced by smoking (67).

Cigarette smoking and gastric cancer. The relationship between the occurrence of stomach cancer and cigarette smoking has been studied since the 1950s. Cigarette smoking has been considered as one of the key risk factors for gastric cancer, which increases the incidence of the disease by approximately 1.5- to 2.5-fold among current smokers (69). Nicotine, the active compound in cigarette smoke, has been demonstrated to be capable of promoting gastric tumor growth and neovascularization (3). In a 20-year follow-up study involving 18,244 middle-aged and older men conducted in Shanghai, China, researchers found that the risk of gastric cancer was statistically significantly higher in ever smokers [hazard ratio (HR), 1.59; 95\% CI, 1.27-1.99] than in non-smokers (70). Furthermore, among the non-drinkers, the ever smokers experienced an $80 \%$ higher risk of gastric cancer (HR, 1.81; 95\% CI, 1.36-2.41). All these observations indicate that cigarette smoking may exert independent effects on the development of gastric cancer. 


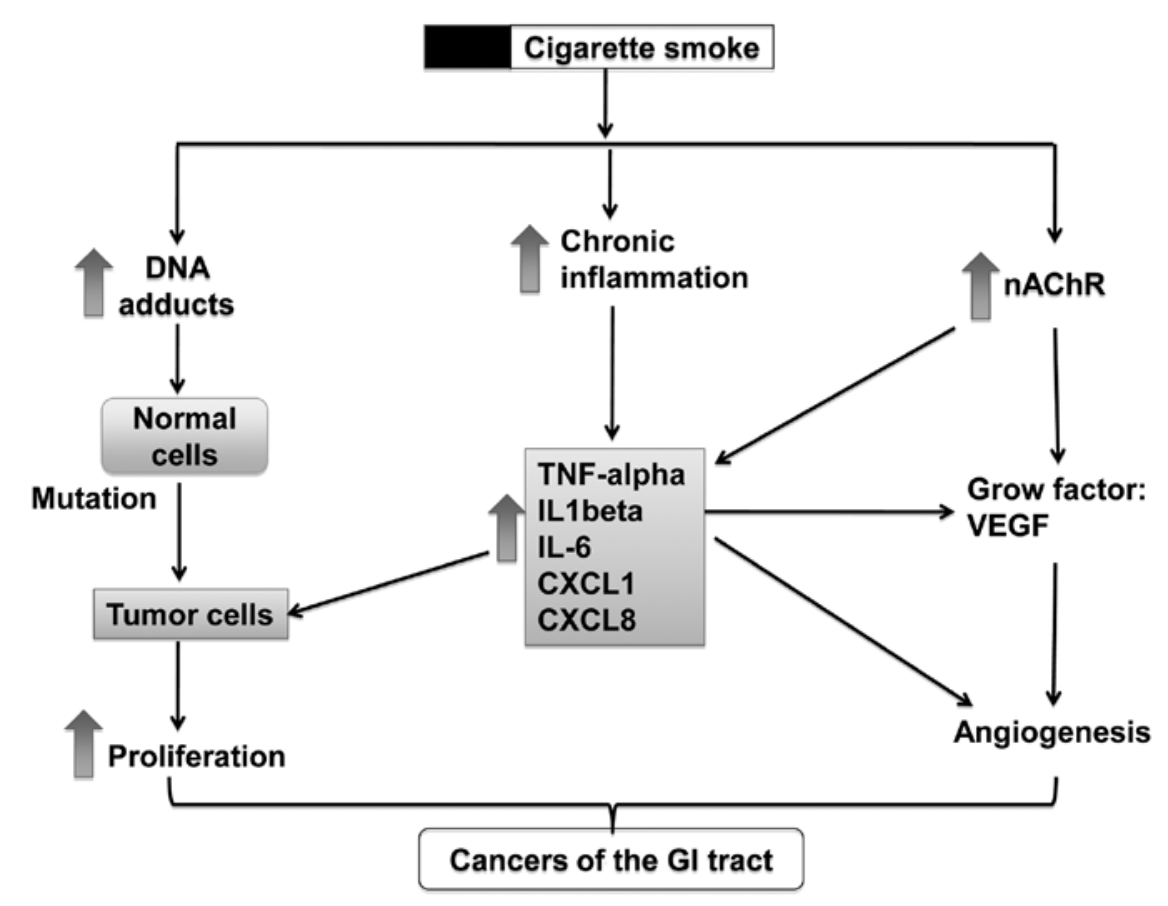

Figure 2. Proposed mechanisms of action of cigarette smoke in tumorigenesis in the GI tract. GI, gastrointestinal; TNF, tumor necrosis factor; IL, interleukin; $\mathrm{nAChR}$, nicotinic acetylcholine receptors; VEGF, vascular endothelial growth factor.

Cigarette smoking causes pancreatic cancer. Tobacco consumption is considered an established risk factor for pancreatic cancer $(71,72)$. In a 10 -year cohort study, researchers found that cigarette smoking was related to an increased risk of the disease [relative risk (RR), 1.7; 95\% CI, 1.6-1.9] and mortality (RR, 1.6; 95\% CI, 1.4-1.7) in patients with pancreatic cancer (72).

Cigarette smoking causes colorectal cancer. Phipps et al (74) carried out a study in 1,968 patients with stage III colon cancer in order to examine the relationship between smoking and cancer outcome. They found that smoking history was significantly associated with a shorter disease-free survival (DFS), and time to recurrence (73) in patients with colon cancer (74). Compared with never-smokers, ever smokers experienced a significantly shorter DFS with a three-year DFS proportion of 70 vs. $74 \%$ (HR, 1.21; 95\% CI, 1.02-1.42). Compared with never-smokers, participants who were former or current smokers were older and were more likely to be male, and to have colon tumors that were dMMR and/or BRAF mutated (74).

Possible effects of smoking on tumorigenesis in the GI tract. Cigarette smoke contains a broad spectrum of toxic and carcinogenic components, such as aromatic amines, phenolic compounds, alkaloids, PAHs, TNSAs, as well as heavy metals $(7,8)$. These toxic and carcinogenic ingredients induce tumorigenesis in the GI tract through several possible mechanisms, including the activation of nicotinic acetylcholine receptors (nAChRs), the formation of DNA adducts, stimulation of tumor angiogenesis, the involvement of immune response and others (Fig. 2). Normally, these mechanisms co-exist and have synergistic effects on the promotion of tumorigenesis. For example, nicotine can activate the nAChRs on cancer cells and induce the release of growth factors, such as vascular endothelial growth factor (VEGF) and IL-1 $\beta$ into the tumor microenvironment, which can increase tumor angiogenesis and therefore promote tumor growth.

$n A C h R s . \mathrm{nAChRs}$ are a family of ligand gate ion channels that function as the key regulators of nicotinic and cholinergic signaling in cells (75). nAChRs are known to participate in cellular adhesion and migration through the interactions with rapsyn and herparan sulphate proteoglycan $(76,77)$. Increasing evidence suggests that nicotine and its derivatives, such as N-nitrosonornicotine and 4-(methylnitrosamino)-1-(3pyridyl)-1-butanonee can directly activate $\mathrm{nAChRs}$ to promote cell growth and angiogenesis and inhibit the drug-induced apoptosis of cancer cells (75).

A recent study demonstrated that nicotine activates Yes-associated protein 1 (YAP1) through nAChR-mediated signaling in esophageal squamous cell cancer (ESCC) (76). Zhao et al (76) reported that nicotine administration increased cell proliferation and migration, and promoted resistance to apoptosis in ESCC. In addition, nicotine administration was also found to induce the nuclear translocation and activation of YAP1 in ESCC. Nicotine signaling can also inhibit the interaction of YAP1 with p63 that contributes to the inhibitory effects of nicotine on cell apoptosis. The association between cigarette smoking and YAP1 activation was also observed in clinical esophageal cancer samples (76). These results suggest that nicotine may be the active compound in cigarette smoke responsible for carcinogenesis in the esophagus.

In our previous studies, we found that nicotine in cigarette smoke may be the most active ingredient responsible for the tumorigenesis of colon cancer cells $(78,79)$. Nicotine was demonstrated to stimulate the proliferation of human colon adenocarcinoma HT-29 cells through the activation of $\alpha 7-n A C h R$ followed by the catecholamine-synthesis pathway and adrenaline release and finally, $\beta$-adrenergic activation (78). 
Furthermore, in an animal study, nicotine was shown to promote tumor growth, mainly by activating the $\beta$-adrenoceptors and the subsequent expression of cyclooxygenase-2, prostaglandin E2, and VEGF in tumor tissues (79). These results demonstrate for the first time the contributory role of $\alpha 7-b A C h R$ and $\beta$-adrenoceptors in the tumorigenesis of colon cancer with significant involvement of some stress hormones.

Formation of DNA adducts. Many toxic compounds in cigarette smoke can interact with DNA to form DNA adducts, which are believed to be another important mechanism for carcinogenesis induced by cigarette smoke (80). Among various ingredients in cigarette smoke, TNSAs are known as the responsible compounds for the formation of DNA adducts (81). In an early clinical study, Dyke et al (81) found that in males only, DNA adducts in gastric tumor tissues from smokers were significantly higher than in those from non-smokers. Nitrosamines and other nitroso compounds in cigarette smoke are capable of covalently interacting with DNA, which alters the normal biological function of DNA and eventually induces carcinogenesis in the GI tract and in urinary bladder $(81,82)$. To date, the formation of DNA adducts has been found in cancer tissues from the oral cavity (83), esophagus (84), stomach (81), pancreas (85) and colon (86).

The tobacco-specific nitrosamine 4-(methylnitrosamino)-1(3-pyridyl)-1-butanone (NNK) has been demonstrated to be one of contributors for smoke-induced pancreatic cancers. It is clear that NNK can react with DNA to form DNA methyl and pyridyloxobutyl adducts (87). These DNA adducts can induce an activating point mutation of the Ki-ras gene in codon 12 , which is common in human pancreatic adenocarcinomas $(88,89)$. Askari et al (89) further demonstrated that NNK induced the transactivation of the EGF receptor, increased the accumulation of intracellular cyclic AMP, and activated the phosphorylation of mitogen-activated protein kinase (MAPK) and ERK1/2. These results indicate that the NNK-mediated $\beta$-adrenergic cAMP-dependent signaling pathway may contribute to the development of pancreatic carcinogenesis in smokers.

Chronic inflammation. The relationship between cancer and inflammation was perceived as early as the 19th century. It is clear that chronic inflammation predisposes to cancer at the proximity of the site of inflammation (90). Chronic inflammation in the GI tract can be caused by $H$. pylori infection, autoimmune diseases, such as IBD and inflammatory conditions, such as peptic ulcers. Various types of immune cells are involved in the formation of the tumor inflammatory microenvironment, such as macrophages, neutrophils, mast cells and lymphocytes. During the inflammatory process, various inflammatory components acting as messengers of inflammation are released by the immune cells and tumor cells in the microenvironment of the neoplastic tissues. These include cytokines, such as tumor necrosis factor- $\alpha$ (TNF- $\alpha)$, interleukin (IL)-1 and IL-6, and chemokines, such as CXCL8. Cigarette smoking is a risk factor for the development of chronic inflammation in the GI tract as reviewed in the previous section, which also promotes inflammation-associated adenoma/ adenocarcinoma formation (91).

Cytokines: a) TNF- $\alpha$. TNF- $\alpha$, as a pro-inflammatory cytokines, can not only induce hemorrhagic necrosis of tumors, but also has protumoral functions. It has been found that a high dose of TNF can destroy the tumor vasculature and cut-off the supplement of $\mathrm{O}_{2}$ and nutrition for tumor growth to exert necrotic effects in tumors (92). However, TNF- $\alpha$ can also induce DNA damage (93), suppress DNA repair (93) and promote the growth of tumor cells (94). Increasing evidence also suggests that TNF- $\alpha$ enhances tumor growth and invasion, angiogenesis, leukocyte recruitment and facilitates epithelial to mesenchymal transition (90). The bidirectional role of TNF- $\alpha$ in tumor progression and cell death is due to the fact that TNF can bind to different membrane-bound homotrimeric receptors, TNFRI and TNFRII, to trigger opposite pathways (95). As regards tumor promotion, TNF- $\alpha$ can inhibit the expression of glycogen synthase kinase-3 $\beta$, and consequently activate the Wnt/ $\beta$-catenin signaling pathway to induce tumor development (96). Furthermore, TNF family members can also suppress the immune response in the tumor environment, which may be due to the inhibition of the major histocompatibility complex class II in tumor-associated macrophages through the decoy receptor-3 (97).

b) $I L-6$. IL-6 plays an important role in tumor development, such as colorectal cancer, in the GI tract (98). Clinical data have shown that IL-6 serum levels from patients with colorectal cancers are significantly increased and positively correlate with tumor load, including tumor size and liver metastases (98). It was demonstrated that two major signaling pathways, the signal transducers and activators of transcription 1 and 3 (STAT1/3) and the Src-homology tyrosine phosphatase 2 (SHP2)-Ras-ERK, are involved in the IL-6-mediated proliferation of intestinal epithelial cells (99). In addition, IL-6 can also promote tumor growth by increasing the colony formation of human colon carcinoma cells (100). These biological actions of IL-6 in colorectal cancer progression were further elucidated by mediating through the soluble IL-6 receptors derived from tumor cells rather than from the membrane-bound receptors (101).

c) $I L-1 \beta$. IL-1 $\beta$ has been found to be capable of promoting tumor cells to metastasize, by activating the cancer-related inflammation cascade $(102,103)$. In models of 3-methylcholanthrene-induced carcinogenesis, it was IL-1 $\beta$, rather than IL-1 $\alpha$ in the tumor microenvironment that was capable of determining the invasive potential of malignant cells, including increased tumor adhesion and invasion, angiogenesis and immune suppression (104). Microenvironmental IL-1 $\beta$ is a required factor for tumor invasiveness and angiogenesis, which may contribute to the production of TNF- $\alpha$ and vascular endothelial cell growth factor by IL-1 $\beta$ (105). Recently, Carmi et al (106) found that myeloid cells released IL-1 $\beta$ and induced endothelial cells to produce proangiogenic factors, such as VEGF, and subsequently provided the inflammatory microenvironment for tumor progression and angiogenesis. Furthermore, they also observed that IL-1 $\beta$ inhibition significantly reduced tumor growth by suppressing inflammation and inducing the maturation of immature myeloid cells into M1 macrophages (106).

Chemokines. Chemokines in the tumor microenvironment are another important factors for modifying tumor growth, and promoting angiogenesis (107) and tumor metastatic spread (108). CXCL1 (growth-regulated oncogene $\alpha$ ) for example, produced by human colorectal cancer cells is capable of inducing microvascular endothelial cell migration and tube formation in vitro. PGE2-induced CXCL1 in the tumor microenvironment has also been found to increase microvessel density and stimulate 
LS-174T cell proliferation in an in vivo model (109). Together with CXCL-1, the angiogenic chemokine CXCL8 (IL-8) was also significantly unregulated in tumor tissues from patients with colorectal cancer (110). CXCL8 signals are mainly activated through the interaction with CXCR1 and CXCR2 present in cancer cells and other cells. To date, CXCR1 and CXCR2 receptors are widely expressed in cancer cells, tumor-associated macrophages, neutrophils and endothelial cells (111). Therefore, the increased CXCL8 levels caused by cigarette smoking could nurture the tumor microenvironment to promote cancer growth (112). Studies have shown that CXCL8 induces cell proliferation by the activation of classical MAPK and downstream phosphorylation of ERK1/2 in neutrophils and cancer cells $(113,114)$. CXCL8 also regulates angiogenesis by the induction of matrix metalloproteinase 9 (MMP-9) through the activation of VEGFR-2 in endothelial cells, and subsequently promotes cancer growth and metastasis (115).

\section{Conclusions}

Mounting evidence demonstrates that cigarette smoking can induce pathogenic and carcinogenic processes in the GI tract. These may lead to severe chronic inflammation and subsequently, the development of cancer at the inflammation sites. Clinical and experimental data have also shown that cigarette smoking is a main risk factor for the induction of inflammatory diseases, such as ulcers and Crohn's disease. Cigarette smoke and its active compounds impair the fundamental structure of the GI tract through the induction of cellular apoptosis and the inhibition of mucosal cell renewal. Cigarette smoke also interferes with the protective mechanisms of the GI tract by decreasing the blood flow in the mucosa and modulating the mucosal immune system. Furthermore, cigarette smoke also inhibits the synthesis and release of EGF and polyamines and thereby, mucus secretion, which plays an important role in protecting mucosal integrity. Chronic inflammation induced by cigarette smoke exposure releases various inflammatory components, including the cytokines, TNF- $\alpha$, IL-1 and IL- 6 , and the chemokines, CXCL1 and CXCL8. These inflammatory components are capable of promoting tumor growth, tumor adhesion and invasion. Moreover, these mediators also induce angiogenesis and immune suppression in the tumor microenvironment. Along with the induction of chronic inflammation, cigarette smoke and its active ingredients can directly activate $\mathrm{nAChRs}$, and form DNA adducts to initiate tumorigenesis in the GI tract. In conclusion, cigarette smoke is a detrimental factor affecting the pathogenesis and tumorigenesis of certain disorders in the GI tract. Detailed mechanistic studies may aid in the development of more effective therapies for various disorders of the GI tract.

\section{References}

1. WHO urges more countries to require large, graphic health warnings on tobacco packaging: the WHO report on the global tobacco epidemic, 2011 examines anti-tobacco mass-media campaigns. Cent Eur J Public Health 19: 133, 151, 2011.

2. Peters SA, Huxley RR and Woodward M: Smoking as a risk factor for stroke in women compared with men: a systematic review and meta-analysis of 81 cohorts, including 3,980,359 individuals and 42,401 strokes. Stroke 44: 2821-2828, 2013.

3. Shin VY and Cho CH: Nicotine and gastric cancer. Alcohol 35: 259-264, 2005
4. Chu KM, Cho $\mathrm{CH}$ and Shin VY: Nicotine and gastrointestinal disorders: its role in ulceration and cancer development. Curr Pharm Des 19: 5-10, 2013.

5. Peluso ME, Munnia A, Srivatanakul P, Jedpiyawongse A, Sangrajrang S, Ceppi M, Godschalk RW, van Schooten FJ and Boffetta P: DNA adducts and combinations of multiple lung cancer at-risk alleles in environmentally exposed and smoking subjects. Environ Mol Mutagen 54: 375-383, 2013.

6. Jain G and Jaimes EA: Nicotine signaling and progression of chronic kidney disease in smokers. Biochem Pharmacol 86: 1215-1223, 2013.

7. Li W, Zhou J, Chen L, Luo Z and Zhao Y: Lysyl oxidase, a critical intra- and extra-cellular target in the lung for cigarette smoke pathogenesis. Int J Environ Res Public Health 8: 161-184, 2011.

8. Zhang L, Ren JW, Wong CC, Wu WK, Ren SX, Shen J, Chan RL and Cho $\mathrm{CH}$ : Effects of cigarette smoke and its active components on ulcer formation and healing in the gastrointestinal mucosa. Curr Med Chem 19: 63-69, 2012.

9. Ross R: The pathogenesis of atherosclerosis: a perspective for the 1990s. Nature 362: 801-809, 1993.

10. Hecht SS: Tobacco carcinogens, their biomarkers and tobaccoinduced cancer. Nat Rev Cancer 3: 733-744, 2003.

11. Ootani H, Iwakiri R, Shimoda R, Nakahara S, Amemori S, Fujise T, Kikkawa A, Tsunada S, Sakata $\mathrm{H}$ and Fujimoto K: Role of Helicobacter pylori infection and nonsteroidal antiinflammatory drug use in bleeding peptic ulcers in Japan. J Gastroenterol 41: 41-46, 2006.

12. Garrow D and Delegge MH: Risk factors for gastrointestinal ulcer disease in the us population. Dig Dis Sci 55: 66-72, 2010.

13. Chen MH, Wu MS, Lee WC, Wang HP and Lin JT: A multiple logistic regression analysis of risk factors in different subtypes of gastric ulcer. Hepatogastroenterology 49: 589-592, 2002.

14. Parasher G and Eastwood GL: Smoking and peptic ulcer in the Helicobacter pylori era. Eur J Gastroenterol Hepatol 12: 843-853, 2000.

15. Andersen IB, Jorgensen T, Bonnevie O, Gronbaek M and Sorensen TI: Smoking and alcohol intake as risk factors for bleeding and perforated peptic ulcers: a population-based cohort study. Epidemiology 11: 434-439, 2000.

16. Ananthakrishnan AN: Environmental risk factors for inflammatory bowel disease. Gastroenterol Hepatol (NY) 9: 367-374, 2013.

17. Zaharie R, Zaharie F, Mocan L, Andreica V, Tantau M, Zdrehus C, Iancu C and Tomus C: Surgical outcome of inflammatory bowel disease - experience of a tertiary center. Chirurgia (Bucur) 108: 812-815, 2013.

18. Lawrance IC, Murray K, Batman B, Gearry RB, Grafton R, Krishnaprasad K, Andrews JM, Prosser R, Bampton PA, Cooke SE, Mahy G, et al: Crohn's disease and smoking: Is it ever too late to quit? J Crohns Colitis 7: e665-e671, 2013.

19. Lunney PC and Leong RW: Review article: Ulcerative colitis, smoking and nicotine therapy. Aliment Pharmacol Ther 36: 997-1008, 2012.

20. Somerville KW, Logan RF, Edmond M and Langman MJ: Smoking and crohn's disease. Br Med J (Clin Res Ed) 289: 954-956, 1984.

21. Seksik P, Nion-Larmurier I, Sokol H, Beaugerie L and Cosnes J: Effects of light smoking consumption on the clinical course of Crohn's disease. Inflamm Bowel Dis 15: 734-741, 2009.

22. Harries AD, Baird A and Rhodes J: Non-smoking: A feature of ulcerative colitis. Br Med J (Clin Res Ed) 284: 706, 1982.

23. Lakatos PL, Vegh Z, Lovasz BD, David G, Pandur T, Erdelyi Z, Szita I, Mester G, Balogh M, Szipocs I, Molnar C, et al: Is current smoking still an important environmental factor in inflammatory bowel diseases? Results from a population-based incident cohort. Inflamm Bowel Dis 19: 1010-1017, 2013.

24. Wu WK and Cho $\mathrm{CH}$ : The pharmacological actions of nicotine on the gastrointestinal tract. J Pharmacol Sci 94: 348-358, 2004.

25. Verschuere $S$, Bracke KR, Demoor T, Plantinga M, Verbrugghe $P$, Ferdinande L, Lambrecht BN, Brusselle GG and Cuvelier CA: Cigarette smoking alters epithelial apoptosis and immune composition in murine GALT. Lab Invest 91: 1056-1067, 2011.

26. Wang H, Ma L, Li Y and Cho CH: Exposure to cigarette smoke increases apoptosis in the rat gastric mucosa through a reactive oxygen species-mediated and p53-independent pathway. Free Radic Biol Med 28: 1125-1131, 2000.

27. Sharma A, Neekhra A, Gramajo AL, Patil J, Chwa M, Kuppermann BD and Kenney MC: Effects of Benzo(e)Pyrene, a toxic component of cigarette smoke, on human retinal pigment epithelial cells in vitro. Invest Ophthalmol Vis Sci 49: 5111-5117, 2008. 
28. FitzGerald AJ, Mandir N and Goodlad RA: Leptin, cell proliferation and crypt fission in the gastrointestinal tract of intravenously fed rats. Cell Prolif 38: 25-33, 2005.

29. Ma L, Wang WP, Chow JY, Yuen ST and Cho CH: Reduction of EGF is associated with the delay of ulcer healing by cigarette smoking. Am J Physiol Gastrointest Liver Physiol 278: G10-G17, 2000.

30. Shin VY, Liu ES, Koo MW, Wang JY, Matsui $\mathrm{H}$ and Cho $\mathrm{CH}$ : Cigarette smoke extracts delay wound healing in the stomach: Involvement of polyamine synthesis. Exp Biol Med (Maywood) 227: 114-124, 2002.

31. Konturek JW, Bielanski W, Konturek SJ, Bogdal J and Oleksy J: Distribution and release of epidermal growth factor in man. Gut 30: 1194-1200, 1989.

32. Ma L, Wang WP, Chow JY, Lam SK and Cho CH: The role of polyamines in gastric mucus synthesis inhibited by cigarette smoke or its extract. Gut 47: 170-177, 2000

33. Brzozowski T, Konturek SJ, Majka J, Dembinski A and Drozdowicz D: Epidermal growth factor, polyamines, and prostaglandins in healing of stress-induced gastric lesions in rats. Dig Dis Sci 38: 276-283, 1993.

34. Konturek JW, Brzozowski T and Konturek SJ: Epidermal growth factor in protection, repair, and healing of gastroduodenal mucosa. J Clin Gastroenterol 13 (Suppl 1): S88-S97, 1991.

35. Maity P, Biswas K, Roy S, Banerjee RK and Bandyopadhyay U: Smoking and the pathogenesis of gastroduodenal ulcer - recent mechanistic update. Mol Cell Biochem 253: 329-338, 2003.

36. Mertz DP and Thongbhoubesra T: Effect of nicotine on the production of gastric acid (author's transl). Med Klin 71: 147-155, 1976 (In German).

37. Ligny G, Van Ccauter J and Henry JP: The effect of cigarette smoking on the cicatrization of duodenal ulcers in patients treated with cimetidine. The role of acid hypersecretion. Rev Med Brux 10: 233-238, 1989 (In French).

38. Fiddian-Green R, Russell RC and Hobsley M: Pyloric reflux in duodenal ulceration and its relationship to smoking. Br J Surg 60 : $321,1973$.

39. Read NW and Grech P: Effect of cigarette smoking on competence of the pylorus: preliminary study. Br Med J 3: 313-316, 1973.

40. Valenzuela JE, Defilippi C and Csendes A: Manometric studies on the human pyloric sphincter. Effect of cigarette smoking, metoclopramide, and atropine. Gastroenterology 70: 481-483, 1976.

41. Bynum TE, Solomon TE, Johnson LR and Jacobson ED: Inhibition of pancreatic secretion in man by cigarette smoking. Gut 13: 361-365, 1972

42. Bochenek WJ and Koronczewski R: Effects of cigarette smoking on bicarbonate and volume of duodenal contents. Am J Dig Dis 18: 729-733, 1973.

43. Murthy SN, Dinoso VP Jr, Clearfield HR and Chey WY: Simultaneous measurement of basal pancreatic, gastric acid secretion, plasma gastrin, and secretin during smoking. Gastroenterology 73: 758-761, 1977.

44. Deng B, Li Y, Zhang Y, Bai L and Yang P: Helicobacter pylori infection and lung cancer: a review of an emerging hypothesis. Carcinogenesis 34: 1189-1195, 2013.

45. Bures J, Kopacova M, Skodova Fendrichova M and Rejchrt S: Epidemiology of Helicobacter pylori infection. Vnitr Lek 57: 993-999, 2011 (In Czech).

46. Ogihara A, Kikuchi S, Hasegawa A, Kurosawa M, Miki K, Kaneko E and Mizukoshi H: Relationship between Helicobacter pylori infection and smoking and drinking habits. J Gastroenterol Hepatol 15: 271-276, 2000

47. Arkkila PE, Kokkola A, Seppälä K and Sipponen P: Size of the peptic ulcer in Helicobacter pylori-positive patients: association with the clinical and histological characteristics. Scand J Gastroenterol 42: 695-701, 2007.

48. Endoh K and Leung FW: Effects of smoking and nicotine on the gastric mucosa: a review of clinical and experimental evidence. Gastroenterology 107: 864-878, 1994.

49. Smith SM and Kvietys PR: Gastric ulcers: Role of oxygen radicals. Crit Care Med 16: 892-898, 1988.

50. Hirota M, Inoue M, Ando Y and Morino Y: Inhibition of stressinduced gastric mucosal injury by a long acting superoxide dismutase that circulates bound to albumin. Arch Biochem Biophys 280: 269-273, 1990.

51. Calvino Fernández M and Parra Cid T: H. pylori and mitochondrial changes in epithelial cells. The role of oxidative stress. Rev Esp Enferm Dig 102: 41-50, 2010.
52. Church DF and Pryor WA: Free-radical chemistry of cigarette smoke and its toxicological implications. Environ Health Perspect 64: 111-126, 1985.

53. Kalra J, Chaudhary AK and Prasad K: Increased production of oxygen free radicals in cigarette smokers. Int J Exp Pathol 72: $1-7,1991$.

54. Sopori M: Effects of cigarette smoke on the immune system. Nat Rev Immunol 2: 372-377, 2002

55. Chow JY, Ma L and Cho CH: Involvement of free radicals and histamine in the potentiating action of cigarette smoke exposure on ethanol-induced gastric mucosal damage in rats. Free Radic Biol Med 24: 1285-1293, 1998.

56. Grivennikov SI, Greten FR and Karin M: Immunity, inflammation, and cancer. Cell 140: 883-899, 2010.

57. Tang Y, Kassie F, Qian X, Ansha B and Turesky RJ: DNA adduct formation of 2-amino-9H-pyrido[2,3-b)indole and 2-amino3,4-dimethylimidazo[4,5-f)quinoline in mouse liver and extrahepatic tissues during a subchronic feeding study. Toxicol Sci 133: 248-258, 2013.

58. Martin JW, Mousa SS, Shaker O and Mousa SA: The multiple faces of nicotine and its implications in tissue and wound repair. Exp Dermatol 18: 497-505, 2009.

59. Zong Y, Zhang ST and Zhu ST: Nicotine enhances migration and invasion of human esophageal squamous carcinoma cells which is inhibited by nimesulide. World J Gastroenterol 15: 2500-2505, 2009.

60. Cucina A, Dinicola S, Coluccia P, Proietti S, D'Anselmi F, Pasqualato A and Bizzarri M: Nicotine stimulates proliferation and inhibits apoptosis in colon cancer cell lines through activation of survival pathways. J Surg Res 178: 233-241, 2012.

61. Seitz HK and Cho CH: Contribution of alcohol and tobacco use in gastrointestinal cancer development. Methods Mol Biol 472: 217-241, 2009.

62. Castellsagué X, Muñoz N, De Stefani E, Victora CG, Castelletto R, Rolón PA and Quintana MJ: Independent and joint effects of tobacco smoking and alcohol drinking on the risk of esophageal cancer in men and women. Int J Cancer 82: 657-664, 1999.

63. Freedman ND, Abnet CC, Leitzmann MF, Mouw T, Subar AF, Hollenbeck AR and Schatzkin A: A prospective study of tobacco, alcohol, and the risk of esophageal and gastric cancer subtypes. Am J Epidemiol 165: 1424-1433, 2007.

64. Yaegashi Y, Onoda T, Morioka S, Hashimoto T, Takeshita T, Sakata K and Tamakoshi A: Joint effects of smoking and alcohol drinking on esophageal cancer mortality in Japanese men: Findings from the Japan collaborative cohort study. Asian Pac J Cancer Prev 15: 1023-1029, 2014.

65. Brown LM, Hoover R, Silverman D, Baris D, Hayes R, Swanson GM, Schoenberg J, Greenberg R, Liff J, Schwartz A, Dosemeci M, et al: Excess incidence of squamous cell esophageal cancer among US Black men: role of social class and other risk factors. Am J Epidemiol 153: 114-122, 2001.

66. Radoï L, Paget-Bailly S, Cyr D, Papadopoulos A, Guida F, Schmaus A, Cénée S, Menvielle G, Carton M,Lapôtre-Ledoux B, Delafosse $\mathrm{P}$, et al: Tobacco smoking, alcohol drinking and risk of oral cavity cancer by subsite: results of a French populationbased case-control study, the ICARE study. Eur J Cancer Prev 22: 268-276, 2013.

67. Pentenero M, Giaretti W, Navone R, Rostan I, Gassino L, Broccoletti R, Arduino PG, Malacarne D and Gandolfo S: Evidence for a possible anatomical subsite-mediated effect of tobacco in oral potentially malignant disorders and carcinoma. J Oral Pathol Med 40: 214-217, 2011.

68. Muwonge R, Ramadas K, Sankila R, Thara S, Thomas G, Vinoda $\mathbf{J}$ and Sankaranarayanan R: Role of tobacco smoking, chewing and alcohol drinking in the risk of oral cancer in Trivandrum, India: a nested case-control design using incident cancer cases. Oral Oncol 44: 446-454, 2008.

69. Sasazuki S, Sasaki S and Tsugane S: Cigarette smoking, alcohol consumption and subsequent gastric cancer risk by subsite and histologic type. Int J Cancer 101: 560-566, 2002.

70. Moy KA, Fan Y, Wang R, Gao YT, Yu MC and Yuan JM: Alcohol and tobacco use in relation to gastric cancer: a prospective study of men in Shanghai, China. Cancer Epidemiol Biomarkers Prev 19: 2287-2297, 2010.

71. Eguchi $\mathrm{H}$ and Nakachi K: Smoking as a risk factor for pancreatic cancer. Nihon Rinsho 64 (Suppl 1): S10-S13, 2006 (In Japanese).

72. Yun JE, Jo I, Park J, Kim MT, Ryu HG, Odongua N, Kim E and Jee SH: Cigarette smoking, elevated fasting serum glucose, and risk of pancreatic cancer in korean men. Int J Cancer 119: 208-212, 2006 
73. Farris SM, Pettrey C and Daly KC: A subpopulation of mushroom body intrinsic neurons is generated by protocerebral neuroblasts in the tobacco hornworm moth, Manduca sexta (Sphingidae, Lepidoptera). Arthropod Struct Dev 40: 395-408, 2011.

74. Phipps AI, Shi Q, Newcomb PA, Nelson GD, Sargent DJ, Alberts SR and Limburg PJ: Associations between cigarette smoking status and colon cancer prognosis among participants in North Central Cancer Treatment Group Phase III Trial N0147. J Clin Oncol 31: 2016-2023, 2013.

75. Schuller HM: Is cancer triggered by altered signalling of nicotinic acetylcholine receptors? Nat Rev Cancer 9: 195-205, 2009.

76. Zhao Y,Zhou W, Xue L, Zhang W and Zhan Q: Nicotine activates YAP1 through nAChRs mediated signaling in esophageal squamous cell cancer (ESCC). PLoS One 9: e90836, 2014.

77. Chernyavsky AI, Arredondo J, Vetter DE and Grando SA: Central role of alpha9 acetylcholine receptor in coordinating keratinocyte adhesion and motility at the initiation of epithelialization. Exp Cell Res 313: 3542-3555, 2007.

78. Wong HP, Yu L, Lam EK, Tai EK, Wu WK and Cho CH: Nicotine promotes cell proliferation via alpha7-nicotinic acetylcholine receptor and catecholamine-synthesizing enzymes-mediated pathway in human colon adenocarcinoma ht-29 cells. Toxicol Appl Pharmacol 221: 261-267, 2007.

79. Wong HP, Yu L, Lam EK, Tai EK, Wu WK and Cho $\mathrm{CH}$ Nicotine promotes colon tumor growth and angiogenesis through beta-adrenergic activation. Toxicol Sci 97: 279-287, 2007.

80. Jarabek AM, Pottenger LH, Andrews LS, Casciano D, Embry MR, Kim JH, Preston RJ, Reddy MV, Schoeny R, Shuker D, Skare J, et al: Creating context for the use of DNA adduct data in cancer risk assessment: I. Data organization. Crit Rev Toxicol 39: 659-678, 2009.

81. Dyke GW, Craven JL, Hall R and Garner RC: Smoking-related DNA adducts in human gastric cancers. Int J Cancer 52: 847-850, 1992.

82. Bartsch H, Ohshima H, Pignatelli B and Calmels S: Human exposure to endogenous $\mathrm{N}$-nitroso compounds: quantitative estimates in subjects at high risk for cancer of the oral cavity, oesophagus, stomach and urinary bladder. Cancer Surv 8: 335-362, 1989.

83. Pabiszczak M, Szmeja Z, Szyfter K and Szyfter W: Analysis of aromatic DNA adducts in oral cavity and pharyngeal cancer. Otolaryngol Pol 54: 151-156, 2000 (In Polish).

84. Lee JM, Liu TY, Wu DC, Tang HC, Leh J, Wu MT, Hsu HH, Huang PM, Chen JS, Lee CJ and Lee YC: Safrole-DNA adducts in tissues from esophageal cancer patients: Clues to areca-related esophageal carcinogenesis. Mutat Res 565: 121-128, 2005.

85. Wang M, Abbruzzese JL, Friess H, Hittelman WN, Evans DB, Abbruzzese MC, Chiao P and Li D: DNA adducts in human pancreatic tissues and their potential role in carcinogenesis. Cancer Res 58: 38-41, 1998.

86. Al-Saleh I, Arif J,El-Doush I, Al-Sanea N, Jabbar AA, Billedo G Shinwari N, Mashhour A and Mohamed G: Carcinogen DNA adducts and the risk of colon cancer: case-control study. Biomarkers 13: 201-216, 2008.

87. Hecht SS: Recent studies on mechanisms of bioactivation and detoxification of 4-(methylnitrosamino)-1-(3-pyridyl)-1-butanone (NNK), a tobacco-specific lung carcinogen. Crit Rev Toxicol 26: 163-181, 1996.

88. Belinsky SA, Devereux TR, Maronpot RR, Stoner GD and Anderson MW: Relationship between the formation of promutagenic adducts and the activation of the K-ras protooncogene in lung tumors from $\mathrm{A} / \mathrm{J}$ mice treated with nitrosamines. Cancer Res 49: 5305-5311, 1989.

89. Askari MD, Tsao MS and Schuller HM: The tobacco-specific carcinogen, 4-(methylnitrosamino)-1-(3-pyridyl)-1-butanone stimulates proliferation of immortalized human pancreatic duct epithelia through beta-adrenergic transactivation of EGF receptors. J Cancer Res Clin Oncol 131: 639-648, 2005.

90. Colotta F, Allavena P, Sica A, Garlanda C and Mantovani A: Cancer-related inflammation, the seventh hallmark of cancer: links to genetic instability. Carcinogenesis 30: 1073-1081, 2009.

91. Liu ES, Ye YN, Shin VY, Yuen ST, Leung SY, Wong BC and Cho CH: Cigarette smoke exposure increases ulcerative colitisassociated colonic adenoma formation in mice. Carcinogenesis 24 1407-1413, 2003

92. van Horssen R, Ten Hagen TL and Eggermont AM: TNF-alpha in cancer treatment: molecular insights, antitumor effects, and clinical utility. Oncologist 11: 397-408, 2006.

93. Wheelhouse NM, Chan YS, Gillies SE, Caldwell H, Ross JA, Harrison DJ and Prost S: TNF- $\alpha$ induced DNA damage in primary murine hepatocytes. Int J Mol Med 12: 889-894, 2003.
94. Charles KA, Kulbe H, Soper R, Escorcio-Correia M, Lawrence T, Schultheis A, Chakravarty P, Thompson RG, Kollias G, Smyth JF Balkwill FR and Hagemann T: The tumor-promoting actions of TNF-alpha involve TNFR1 and IL-17 in ovarian cancer in mice and humans. J Clin Invest 119: 3011-3023, 2009.

95. Idriss HT and Naismith JH: TNF alpha and the TNF receptor superfamily: structure-function relationship(s). Microsc Res Tech 50: 184-195, 2000.

96. Oguma K, Oshima H, Aoki M, Uchio R, Naka K, Nakamura S, Hirao A, Saya H, Taketo MM and Oshima M: Activated macrophages promote Wnt signalling through tumour necrosis factor-alpha in gastric tumour cells. EMBO J 27: 1671-1681, 2008.

97. Chang YC, Chen TC, Lee CT, Yang CY, Wang HW, Wang CC and Hsieh SL: Epigenetic control of MHC class II expression in tumor-associated macrophages by decoy receptor 3 . Blood 111: 5054-5063, 2008

98. Chung YC and Chang YF: Serum interleukin-6 levels reflect the disease status of colorectal cancer. J Surg Oncol 83: 222-226, 2003

99. Tebbutt NC, Giraud AS, Inglese M, Jenkins B, Waring P, Clay FJ, Malki S, Alderman BM, Grail D, Hollande F, Heath JK and Ernst M: Reciprocal regulation of gastrointestinal homeostasis by SHP2 and STAT-mediated trefoil gene activation in gp130 mutant mice. Nat Med 8: 1089-1097, 2002.

100. Schneider MR, Hoeflich A, Fischer JR, Wolf E, Sordat B and Lahm H: Interleukin-6 stimulates clonogenic growth of primary and metastatic human colon carcinoma cells. Cancer Lett 151: 31-38, 2000.

101. Becker C, Fantini MC, Schramm C, Lehr HA, Wirtz S, Nikolaev A, Burg J, Strand S, Kiesslich R, Huber S, Ito H, et al: TGF-beta suppresses tumor progression in colon cancer by inhibition of IL-6 trans-signaling. Immunity 21: 491-501, 2004.

102. Candido $\mathrm{J}$ and Hagemann T: Cancer-related inflammation. J Clin Immunol 33 (Suppl 1): S79-S84, 2013

103. Luo JL, Tan W, Ricono JM, Korchynskyi O, Zhang M, Gonias SL, Cheresh DA and Karin M: Nuclear cytokineactivated IKKalpha controls prostate cancer metastasis by repressing Maspin. Nature 446: 690-694, 2007.

104. Krelin Y, Voronov E, Dotan S, Elkabets M, Reich E, Fogel M, Huszar M, Iwakura Y, Segal S, Dinarello CA and Apte RN: Interleukin-1beta-driven inflammation promotes the development and invasiveness of chemical carcinogen-induced tumors. Cancer Res 67: 1062-1071, 2007.

105. Voronov E, Shouval DS, Krelin Y, Cagnano E, Benharroch D, Iwakura Y, Dinarello CA and Apte RN: IL-1 is required for tumor invasiveness and angiogenesis. Proc Natl Acad Sci USA 100: 2645-2650, 2003.

106. Carmi Y, Dotan S, Rider P, Kaplanov I, White MR, Baron R, Abutbul S, Huszar M, Dinarello CA, Apte RN and Voronov E: The role of IL-1 $\beta$ in the early tumor cell-induced angiogenic response. J Immunol 190: 3500-3509, 2013.

107. Dimberg A: Chemokines in angiogenesis. Curr Top Microbiol Immunol 341: 59-80, 2010.

108. Wilson J and Balkwill F: The role of cytokines in the epithelial cancer microenvironment. Semin Cancer Biol 12: 113-120, 2002.

109. Wang D, Wang H, Brown J, Daikoku T, Ning W, Shi Q, Richmond A, Strieter R, Dey SK and DuBois RN: CXCL1 induced by prostaglandin E2 promotes angiogenesis in colorectal cancer. J Exp Med 203: 941-951, 2006.

110. Erreni M, Bianchi P, Laghi L, Mirolo M, Fabbri M, Locati M, Mantovani A and Allavena P: Expression of chemokines and chemokine receptors in human colon cancer. Methods Enzymol 460: 105-121, 2009.

111. Gales D, Clark C, Manne U and Samuel T: The chemokine CXCL8 in carcinogenesis and drug response. ISRN Oncol 2013: $859154,2013$.

112. Vandercappellen J, Van Damme J and Struyf S: The role of CXC chemokines and their receptors in cancer. Cancer Lett 267: 226-244, 2008.

113. Luppi F, Longo AM, de Boer WI, Rabe KF and Hiemstra PS: Interleukin-8 stimulates cell proliferation in non-small cell lung cancer through epidermal growth factor receptor transactivation. Lung Cancer 56: 25-33, 2007.

114. Richardson RM, Ali H, Pridgen BC, Haribabu B and Snyderman R: Multiple signaling pathways of human interleukin-8 receptor A. Independent regulation by phosphorylation. J Biol Chem 273: 10690-10695, 1998 .

115. Inoue K, Slaton JW, Eve BY, Kim SJ, Perrotte P, Balbay MD, Yano S, Bar-Eli M, Radinsky R, Pettaway CA and Dinney CP: Interleukin 8 expression regulates tumorigenicity and metastases in androgen-independent prostate cancer. Clin Cancer Res 6: 2104-2119, 2000. 